\title{
Life Lessons: Two Experts on Death and Dying Teach Us about the Mysteries of Life and Living Elisabeth Kübler-Ross, David Kessler (Simon and Schuster)
}

\author{
Un Sun Chung ${ }^{1,2}$ \\ 'Department of Psychiatry, Kyungpook National University Children's Hospital, Daegu, Korea \\ ${ }^{2}$ Department of Psychiatry, Division of Child and Adolescent of Psychiatry, University of Florida, FL, USA
}

Received: June 19, 2019

Address for correspondence: Un Sun Chung, Department of Psychiatry, Kyungpook National University Children's Hospital, 807 Hoguk-ro, Buk-gu, Daegu 41404, Korea

Tel: +82-53-200-3771, Fax: +82-53-420-5747, E-mail: chungunsun@hanmail.net

ISBN: 978-1-4767-7553-1

Copyright 2000

Updated August 2014 edition, prefaced by David Kessler

Published in New York by Scribner, a division of Simon \& Shuster

Shortly after arriving in Florida, United States, as a oneyear visiting scholar, I received a request to write a book review for the Journal of the Korean Academy of Child and Adolescent Psychiatry.

I first considered The Better Angels of Our Nature: Why Violence Has Declined by Steven Pinker. It discusses the history of human violence, a topic I have often pondered upon since the murder of renowned Korean psychiatrist, Dr. Sewon Rim, by his own patient on the final day of 2018 .

For years, I have been very busy as a mother of eleven-yearold twins. It was very important for me to see my children become well-adjusted and happy at the same time to indulge in my professional career. Hoping they could experience the thrill of becoming members of their school band, I wrote an email to the instructor to see if they would be permitted to join the band in the middle of the third quarter. She promptly answered my email within an hour. I was very impressed by her encouraging, detailed, and sincere response despite the initial disappointment that my children would not be able to start immediately. Instead, they would be welcome to join at the beginning of the new school year in September.

During spring vacation, we visited a local music store to find appropriate instruments for the children, without reser-

This is an Open Access article distributed under the terms of the Creative Commons Attribution Non-Commercial License (https://creativecommons.org/licenses/by-nc/4.0) which permits unrestricted non-commercial use, distribution, and reproduction in any medium, provided the original work is properly cited. vation or suggestion of what might be most suitable for them. After introductions, one sales representative spent more than ninety minutes discussing nine different band instruments and gave the children chances to test each of them. To our surprise, the man is a drum teacher, and also the lead percussionist in the regional Orchestra, as we found out later after attending a concert. Our family was very thankful and impressed by this person who had sincerely shared these moments and his talents with us.

During this visit, at some point of the conversation, I accidentally discovered that the school band conductor who had earlier written the warm welcome letter is now dealing with serious family issues. She is now pregnant and expecting her first baby soon. Parallel to this news, her husband was diagnosed with terminal cancer last year. This was shocking news to me, even though I have still not met her in person. Imagine delivering your first child while watching your husband facing death at the same time. I haven't stopped thinking of her since, partly because I am a professional who deals with grief after loss and also because I am a mother and wife myself. I keep wondering how I might possibly support her as a stranger and as a professional in another country with a different culture and language. To that end, I ordered this book, Life Lessons: Two Experts on Death and Dying Teach Us about the Mysteries of Life and Living, with hopes that it might provide support and comfort to her and her husband.

I cannot count how many copies of this book I have purchased. I have given Korean versions as presents to others who are suffering the hardest of times. Some are my teachers, friends, students, and my colleagues. I have also given them to patients and their families, as well as to teachers after the loss of their own students. I believe this book can help people just like it 
helps me whenever I refer back to it during confusing times, after stumbling or feeling betrayed by life.

I had already read the English version of the book but left it behind in Korea; therefore, I borrowed a copy from the library to read it again. When I compared the library edition to the new one I had purchased for the band conductor, I noticed that a new preface written by the co-author, David Kessler, had been added to the 2014 tenth anniversary edition. As soon as I read the new preface, I knew it was worth buying another copy for myself. The preface contains Kessler's personal anecdotes regarding life lessons experienced after the original publication of the book, thereby teaching us through additional stories while openly exposing their impact on the author and his reactions.

The co-authors of Life Lessons: Two Experts on Death and Dying Teach Us about the Mysteries of Life and Living are Elisabeth Kübler-Ross and the aforementioned Kessler. Most of us are very familiar with Kübler-Ross. As psychiatrists, we learned her theories of the five stages of bad news-including death sentences or diagnoses of cancer-from our psychiatry textbooks in medical school. Kübler-Ross herself had experienced paralysis of the left side of her body after a stroke and was bed ridden for the final years of her life and died in 2004. Her theories comforted many dying people, and this book was ultimately derived from what was learned from those who are were at the edge of their lives.

The English version of the book has two hundred and twelve pages plus acknowledgments, a preface to the anniversary edition, individual messages from Kübler-Ross and Kessler, and a note to the reader. The main content is divided into fourteen chapters, each explaining one lesson related to authenticity, love, relationships, loss, power, guilt, time, fear, anger, play, patience, surrender, forgiveness to happiness, and a final lesson. Also included are a reading group guide, a guide for further discussion and an additional resource section.

Although uncertain because I don't have the Korean version with me in United States, I believe the last three sections-the reading group guide, the guide for further discussion, and additional resources-are new additions to the updated 2014 version. As a mental health professional providing support in times of death and grief, the resource section provides abundant information of utmost importance that I really want and need to know. I could have spent an entire year digging through these resources, and then I would still need to translate and introduce them in a culturally appropriate manner for Korea.

Without doubt, you might ask yourselves the following: "If I keep doing what I'm currently doing, won't I just experience more of the same? Is that what I want, or do I want a higher quality of life, to be more loving and more peaceful?" (Kessler, page xi, anniversary edition preface). As human be- ings and as professionals, helping patients and their families find the appropriate answers can enrich the lives of everyone involved.

Kessler suggests that he grew to understand the book as a journey toward happiness. Each time he read it, he came across a new revelation. This mirrors my experiences of opening this book whenever I feel lost or unhappy in life's journey. I usually highlight the lines I find most appealing to me, and each time those lines are different depending on my age, maturity, circumstances, accumulated experiences, and current issues. During this latest reading, I found myself highlighting more passages in the chapter related to forgiveness, a lesson I need to learn at this time. I had no choice but to smile when I realized this self-revelatory fact while laughing at my own narrow mindedness and awareness of the depth of hurt. This book enables me to rely on humor even at the very moment of facing my insignificance after repetitive reading. It became a soulmate and companion in a lonely passage through one stage of my life.

I like the word "authenticity" very much, first encountered in the autobiography of my favorite painter, Paul Klee. He chose this word to explain the reason why he decided to be a painter even though he had been very gifted violinist, writing that as a painter, he was able to keep his own authenticity more. While explaining each individual's own authenticity in the first chapter, I like the pie metaphor used by the dying grandmother in her late seventies when consoling her grandson who couldn't let her go.

"We are like a pie. We give a piece to our parents, we give a piece to our loved-ones, we give a piece to our children, and we give a piece to our careers. As the end of life approaches, some people have not saved a piece for themselves and don't even know what kind of pie they were. I know what kind of pie I am; this is something each of us finds for ourselves. I can leave this life knowing who I am... You don't have to wait until you are dying to find out what kind of pie you are" (p. 18). I would really like to save some pieces of pie for myself and would prefer to know what kind of pie I am as soon as possible. If that is impossible, at least I would like to be delicious!

In the chapter of love, the authors posit that most of us never learned how to love ourselves as children, thereby making it difficult to love ourselves throughout life (p. 27). When we were young, most of us never really experienced true love; we only experienced rewards. We must learn how to nurture our soul and begin to practice being as kind and forgiving to ourselves as we are taught to be to others (p. 28). During life's fluctuations, we cannot solve all of our loved ones' problems, but we can usually be there for those we truly love (p. 31). Being there is everything in love, in life, and in dying (p. 33), albeit not as easy as it appears. 
Among the lessons of relationships, I have often repeated this sentence to my patients, "The wrong people can often be our greatest teachers." This is also true for those in our life we didn't choose, most often our nuclear families of parents and siblings. As we struggle to cope or find common ground with these people, opportunities arise to become more loving or compassionate (p. 47).

As this book is based on the experiences of dying people, it is replete with precious lines regarding the lessons of loss. Some of them follow: "If life is a school, loss is a major part of the curriculum" (p. 56). "Life is loss and loss is life" (p. 58). "Loss is one of our most difficult lessons in life" (p. 60). "Loss unifies us, deepens our understanding of each other, and connects us to one another like no other lesson of life can" (p. 63). This is exactly what we experienced as Psychistrists after the Sewol ship-sinking disaster at the Danwon High School, where more than two hundred fifty students and teachers died and missed after ship sinking accident during the school trip in 2014. We gathered as soon as possible wherever they need us and tried to connect with one another as a whole.

It is often true for children or teenagers who lose parents: "They may not experience much grief until they become adults and can handle it" (p. 67). "New losses trigger old ones" (p. 67). Grief is always individualized. We will all heal in our own time and in our own way (p. 69). Are these essential and simple?

In the lesson related to power, we are reminded that this is our life and only we have the power to make ourselves happy (p. 81). As gratitude generates power, a grateful person is a powerful person. We find true power, happiness, and well-being in the fine art of gratitude (p. 83).

In the lesson on guilt, we learn that we are trained to be codependent, and a clear symptom of codependency is the ability to say "no" (p. 88). Guilt is a connection to our weaknesses, our shame, and our unforgiveness. The guilt that attacks your conscience becomes the shame that assaults your soul (p. 92). Since guilt always comes from the past, it offers a way to avoid the reality of the present. Only when we release our guilt can we truly move beyond our past to create a new future (p. 95). The key to healing is forgiveness, part of which means acknowledging the past and letting it go (p. 96).

When reading the lesson about time, it reminded me of an interview with Kang In Lee, the 18-year-old Korean soccer player who had just won the Golden Ball at the U20 World Cup on June 16, 2019. Lee said "I have no regrets. Why cry?" When we have truly lived our lives, we don't want or need to live them again. It's the parts of life that were not lived that we regret (p. 101). The young player had tried his best and felt no regrets even though Korea lost in the championship final game.

As child psychiatrists, many of our patients live with fear.
The lesson on fear offers plenty of wisdom. The authors use the acronym FEAR, that is, False Evidence Appearing Real (p. 111). Fear wears many disguises, including anger, protectionism, and self-sufficiency, and the fear itself foments considerable unhappiness in life (p. 121). Having compassion for others as well as ourselves melts away fear (p. 122). You can find the secret to achieve this for yourself by reading this book.

There are many angry people around us, especially in modern Korea. Our society considers anger to be abhorrent; therefore, we have not developed healthy ways to externalize it (p. 133). We reject it, deny it, or try to contain it until we implode (p. 133). A better solution would be to learn to be more honest, express our anger, and live our lives with the mindset that feelings of anger have come and passed rather than let anger become a perpetual state of being (p. 136).

As child psychiatrists, we know that we cannot ignore the importance of play. If you read Kessler's preface to the anniversary edition, you might sense a heartfelt kinship with the author based on similar experiences that are both touching and bitter. Play is a fun experience that transcends all boundaries (p. 140). All members of society need to play together more often, especially these days as we are experiencing divisions caused in part by having a higher proportion of people with multicultural backgrounds.

In the lesson about patience, we encounter a frank confession from Kübler-Ross's own experiences of helplessness when captured inside her paralyzed body. Patience is connected with time and trust. If we trust others, we can be more patient with them (p. 161).

The lesson of surrender is not easy to understand. It is also connected with patience and power. We hear Kübler-Ross's voice as she discusses her own ongoing issues, thereby touching our minds and eliciting our compassion for her. In essence, she is saying that if we don't feel at peace, if life doesn't flow, if we feel that we are responsible for everything, and if we want to change what cannot be changed, then it's time to surrender (p. 174). For us to surrender, we must learn to find the good in the bad (p. 176). Letting things happen and just go is a wonderful gift for ourselves in our life with ups and downs; surrendering (p. 174).

In the lesson of forgiveness, we notice that the person we most often need to forgive is, ironically, ourselves. We must forgive ourselves for what we have and have not done (p. 184). Without forgiveness, we continuously hurt ourselves. They say forgiving is a lifelong task, a so-called spiritual maintenance plan (p. 185).

For the lesson of happiness, our happiness is determined by how we interpret in a cognitive way and perceive in an emotional way what happens in our state of mind, and also by our commitment choosing it consciously (p. 190). Happiness comes 
from real experiencing moments of it (p. 191). Making comparisons is probably the shortest route to unhappiness (p. 191), and comparing ourselves to our past or future can do the same (p. 191). Practice being happy all the time. Practice being kind to others. If you want to take the advanced course, practice kindness anonymously (p. 197). Learn to choose happiness all the time; take only the paths that make you feel good about life (p. 198).

I will not summarize the final lesson as it is worth reading yourselves. Sometimes I read this book in Korean in its entirety; often I start from a randomly opened page. When I read this in English, it becomes a new book to me. I still shed tears when I read the stories, many of which remind me of my Korean patients. This motivates me to try to devise and deliver useful lessons for them.

To date, I have not given this book to the band conductor who has preparing to welcome her first baby into the world while bracing herself to say goodbye to her partner because I had to highlight lines in the new book for myself. I will buy another one for her. Thanks to her, I read this book again and I feel honored to find that I might have needed it as much or more than her this time of my life. With so many life lessons to review, I am pleased that I already practice some of them in my own life. I now feel qualified to share my lessons and knowledge with this fine woman and her family, just as the drummer in the music store had shared his expertise with my family. I hope that her baby and her husband might spend time together for a long time enough for him to give him/her his own life lessons. I also hope that other professionals can benefit from the life lessons in this book during their darkest moments of life's journey and then share them with their patients, family, and friends. 